\title{
Filtering Properties of Porous Ceramics with Unidirectionally Aligned Pores
}

\author{
Takayuki FUKASAWA, Motohide ANDO* and Tatsuki OHJI** \\ Power Supply Materials \& Devices Laboratory, Corporate Research \& Development Center, Toshiba Corporation, \\ 1, Komukai Toshiba-cho, Saiwai-ku, Kawasaki-shi 212-8582 \\ *Synergy Ceramics Laboratory, Fine Ceramics Research Association (FCRA), Shimo-Shidami, Moriyama-ku, Nagoya-shi 463-8687 \\ **Synergy Materials Research Center, National Institute of Advanced Industrial Science and Technology (AIST), \\ Shimo-Shidami, Moriyama-ku, Nagoya-shi 463-8687
}

\section{配向気孔を有するセラミックス多孔体のフィルター特性 \\ 深澤孝幸·安藤元英*·大司達樹**}

(株)東芝研究開発センター給電材料・デバイスラボラトリー, 212-8582 川崎市幸区小向東芝町 1

*ファインセラミックス技術研究組合・シナジーセラミックス研究所, 463-8687 名古屋市守山区大字下志段味字穴ヶ洞 2268-1

**産業技術総合研究所シナシーマテリアル研究センター, 463-8687 名古屋市守山区大字下志段味字穴ヶ洞 2268-1

\begin{abstract}
Among porous ceramic with unidirectionally aligned pores, synthesized from a water-based slurry using unidirectional freezing and freeze-drying process, porous silicon nitride showed a characteristic microstructure wherein the macroscopically aligned open pores contained many fibrous grains protruding from their internal walls. Pressure loss of the porous material was measured at room temperature using a filter media tester. A filtering test using fly ash was carried out with a reverse air-cleaning at constant intervals. The developed material had a low pressure loss and a strength which could withstand use. Air-cleaning worked effectively through the aligned pores and almost $100 \%$ of the ash was trapped, maintaining low pressure loss.

[Received November 14, 2001; Accepted April 18, 2002]
\end{abstract}

Key-words : Porous ceramic, Aligned pores, Freeze-dry, Pressure loss, Filter test

\section{Introduction}

Porous ceramics with open pores are considered for use in separation filters, catalysis supports and other industrial applications. Such applications are often used in fluid flow. Therefore, it is necessary to reduce pressure loss as much as possible. So far, we have developed a porous ceramic with unidirectionally aligned pores to reduce pressure loss. ${ }^{1)-4)}$ It was synthesized from a water-based slurry using a unidirectional freezing and freeze-drying process. In this process, the aligned pores were produced by sublimation of columnar ice which was formed during unidirectional freezing in the slurry. Freeze-drying was used to make the ice sublimate without thawing. The aligned pores were maintained after the sintering. The porous material obtained by this method had aligned open pores of several tens of micrometers in size, which has been reported in only a few papers. ${ }^{5)-8)}$ Using this method, the pore size and microstructure can be changed easily by controlling freezing and sintering temperatures. Furthermore, it had a characteristic microstructure. For example, a porous silicon-nitride showed a unique microstructure wherein the macroscopic aligned pores contained many fibrous grains protruding from their internal walls. ${ }^{3)}$ Such a pore structure is thought to be preferable for trapping soot dust from polluted air. However, there has been no report on filtration performance of porous material which had such pore structure and pore size.

In this paper, we prepared some porous $\mathrm{Si}_{3} \mathrm{~N}_{4}$ with different aligned pore sizes and microstructures. Pressure loss of the porous material was measured and a filtering property using fly ash was evaluated. The effect of the structural characteristics of porous ceramics on filtration performance was investigated.

\section{Experimental procedure}

2.1 Sample preparation

$\mathrm{Si}_{3} \mathrm{~N}_{4}$ powder (SN-ESP; Ube Industries, Ltd., Tokyo) was mixed with additives: 5 mass $\% \mathrm{Y}_{2} \mathrm{O}_{3}$ (RU-P; Shin-Etsu Chemical Co., Tokyo) and 2 mass $\% \mathrm{Al}_{2} \mathrm{O}_{3}$ (TM-D; Taimei Chemical Co., Nagano). The mixed powder (denoted by 5Y2A) was ball-milled with nylon balls in distilled water for about $20 \mathrm{~h}$. A small amount of dispersant was used to increase slurry dispersion. The slurry's concentration was 20 vol\%. The mixed powder with additive reduced in amounts of 1 mass $\% \quad \mathrm{Y}_{2} \mathrm{O}_{3}$ and 0.5 mass $\% \quad \mathrm{Al}_{2} \mathrm{O}_{3}$ (denoted by $1 \mathrm{Y} 0.5 \mathrm{~A}$ ) was also prepared. Resultant slurry was de-aired by stirring in a vacuum dessicator. It was poured into a cylindrical container and only the container bottom face was immersed in a refrigerant in a freezing bath as shown in Fig. 1.1)-4) The container was composed of two parts: the container bottom made of metal with high thermal conductivity and the side made of fluorocarbon polymer. The container diameter was $75 \mathrm{~mm}$. Ethanol cooled at -25 or $-80^{\circ} \mathrm{C}$ was used as the refrigerant. The top of the container

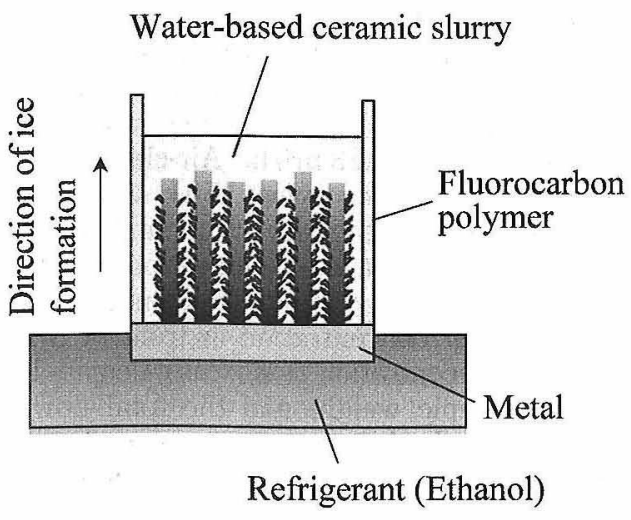

Fig. 1. Schematic of freezing process. The slurry was frozen from the container's bottom in a vertical direction. 
Table 1. Preparation Conditions of Samples Used in This Study

\begin{tabular}{ccccc}
\hline Sample & Additives & $\begin{array}{c}\text { Freezing } \\
\text { temperature } /{ }^{\circ} \mathrm{C}\end{array}$ & $\begin{array}{c}\text { Sintering } \\
\text { temperature } /{ }^{\circ} \mathrm{C}\end{array}$ & Porosity /\% \\
\hline SN-1 & $5 \mathrm{Y} 2 \mathrm{~A}$ & -80 & 1700 & 66.5 \\
$\mathrm{SN}-2$ & $5 \mathrm{Y} 2 \mathrm{~A}$ & -80 & 1850 & 62.8 \\
$\mathrm{SN}-3$ & $5 \mathrm{Y} 2 \mathrm{~A}$ & -25 & 1700 & 66.2 \\
$\mathrm{SN}-4$ & 1Y0.5A & -80 & 1700 & 69.5 \\
\hline
\end{tabular}

was open so that the upper surface of the slurry would meet the atmosphere at room temperature. Thus, the ice was stimulated to grow macroscopically in a vertical direction. After the slurry completely froze, the container was freezedried in a vacuum vessel to prevent thawing. The columnar pores were generated by sublimation of the ice.

Samples were carefully taken off the container after drying for about $24 \mathrm{~h}$. Green compacts were placed in a graphite crucible coated with boron nitride and sintered at $1700^{\circ} \mathrm{C}$ or $1850^{\circ} \mathrm{C}$ for $2 \mathrm{~h}$ under a $0.8 \mathrm{MPa}$ nitrogen atmosphere. These sintering temperatures were chosen to change microstructure inside of the aligned pore. Samples used in this study are listed in Table 1.

All samples shrank about 15\% in diameter during sintering, and the shrinkage was independent of the sintering temperature and the amount of the additive. They were machined into about $13 \mathrm{~mm}$ thickness so that their orientations would correspond with that of the aligned pores. They were used for the filter test.

\subsection{Characterization}

Porosity was calculated from sample dimensions and weight using the $\mathrm{Si}_{3} \mathrm{~N}_{4}$ theoretical density. Porous $\mathrm{Si}_{3} \mathrm{~N}_{4}$ microstructure was observed by a scanning electron microscope (SEM; JEOL, JSM-5600).

Samples were dried in a vacuum at $350^{\circ} \mathrm{C}$ for $2 \mathrm{~h}$ to remove the absorption before measurement of pore size distribution. Pore size distribution was measured by mercury porosimetry (Quanta Chrome, PoreMaster-33P-GT).

\subsection{Filtering test}

A filter media tester from Hosokawa Micron Co. was used in this study. This machine is a measurement device based on the German VDI standard 3926. Figure 2 shows a schematic of the device. A ceramic sample was set on the fork toward the horizontal flow. Air-flow rate was controlled by establishing negative pressure behind the sample. The pressure drop of the sample was measured as a difference in pressure in front of and behind the sample. The effective filtering area was $12.56 \mathrm{~cm}^{2}$.

The air containing the fly ash was fed from the top of the device. A standard fly ash (Japanese Industrial Standard, JIS Z8901), with average particle size of $4.4 \mu \mathrm{m}$, was used. In this filtration test, the horizontal flow rate (through the sample) was fixed at $0.23 \mathrm{~m}^{3} / \mathrm{h}$. Air-cleaning from the reverse direction was done every $150 \mathrm{~s}$. A change of the residual pressure loss for the repetition number of air-cleaning was measured. A fly ash concentration in vertical flow (C1) was measured by a photometric concentration monitor. It means a dust concentration in front of the sample. Horizontal dust concentration (C2) was calculated from the change in the sample weight and the total flow mass in horizontal direction. In this case, the last sample weight was measured after stopping the dust feed and doing ten times air-cleaning from reverse direction. Fly ash trapping efficiency, $\eta$ was calculated from the following equation.

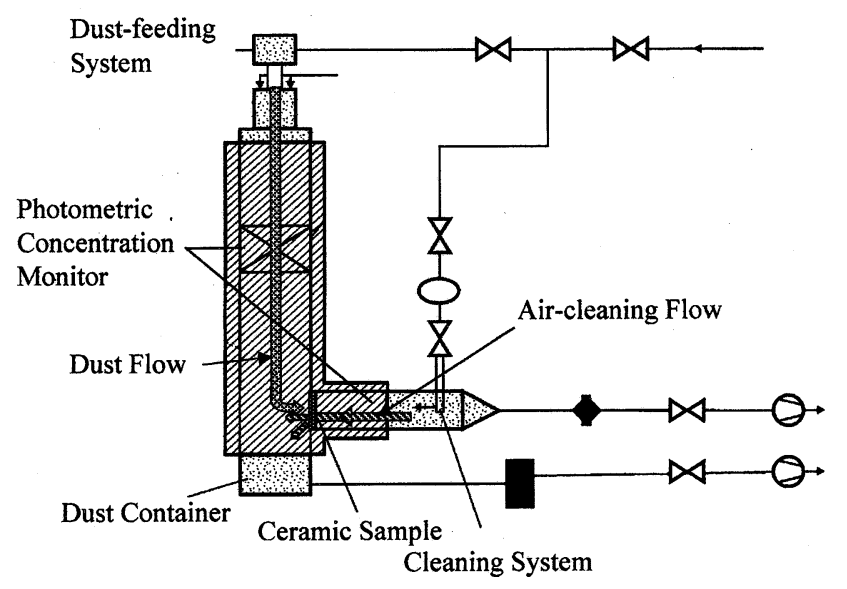

Fig. 2. Schematic of filter media tester. A ceramic sample was set on the fork toward the horizontal flow.

$$
\eta=(1-\mathrm{C} 2 / \mathrm{C} 1) \times 100
$$

\section{Results and discussion}

3.1 Properties of porous $\mathrm{Si}_{3} \mathrm{~N}_{4}$

It was reported that porosity can be controlled by slurry concentration in this freeze-drying process. ${ }^{2), 3)}$ Porosity of the porous $\mathrm{Si}_{3} \mathrm{~N}_{4}$ ceramics obtained is shown in Table 1. All samples had macroscopic aligned pores formed by sublimation of columnar ice. Typical microstructure is shown in Fig. 3. The macroscopic open pores with flat shape were observed in the matrix. The details have been reported in the previous papers. ${ }^{1)-4)}$ Figure 4 shows microstructure for samples sintered at different temperatures. It shows a topview magnification for one of the macroscopically aligned open pores. The pores aligned in a direction of ice formation. According to this method, a pleat-shaped structure caused by dendrite formation during the freezing process was always formed in the internal wall of the aligned pore. Little grain growth was observed for materials sintered at $1700^{\circ} \mathrm{C}$. On the other hand, a great number of the fibrous $\mathrm{S}_{3} \mathrm{~N}_{4}$ grains protruding from the internal wall of the aligned pore were observed for the material sintered at $1850^{\circ} \mathrm{C}$. Grain growth on the internal wall was only affected by sintering temperature. Furthermore, in the case of material with reduced additive, the matrix wall itself seemed to be more porous.

Pore size distributions analyzed by mercury porosimetry are shown in Fig. 5. In the previous paper, it was revealed that almost all the pores were open ones. ${ }^{\left.1{ }^{1-4}\right)}$ Samples sintered at $1700^{\circ} \mathrm{C}$ had bimodal distribution. The large size of the pores indicates that they are macroscopic aligned open pores. As the aligned pore had a flat-shaped section as shown in Fig. 3, the narrowest part of the pore can be detected by the mercury intrusion method. On the other hand, the small-sized ones are minute pores on internal wall of the aligned pores. The intermediate-sized pores are detected for the material sintered at $1850^{\circ} \mathrm{C}$. These pores are very likely produced between the fibrous grains formed in the internal wall of the aligned pores. ${ }^{3)}$ The aligned pore size was small when the sintering temperature was high and the freezing temperature was low. Pore size for the material sintered at $1850^{\circ} \mathrm{C}$ seemed to be small in appearance because the fibrous grains blocked the pore as shown in Fig. 4(b). These samples were used for the filtering test.

3.2 Filtering properties

Figure 6 shows a pressure drop of the sample with a face 


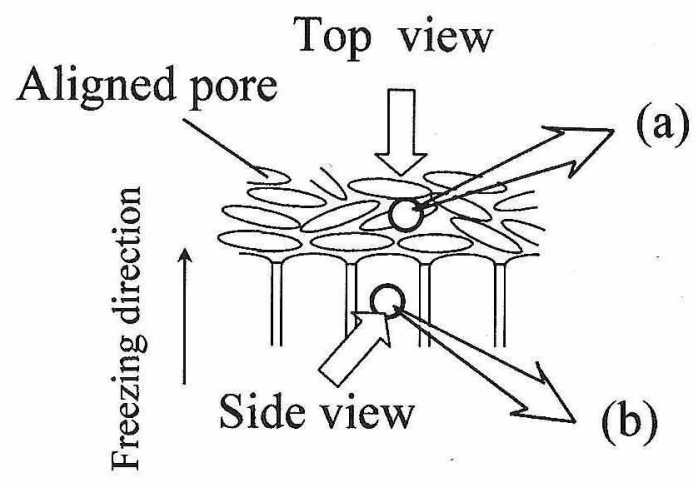

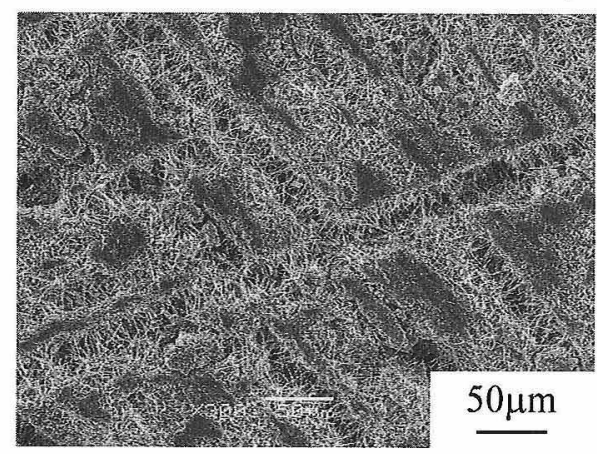

(a)

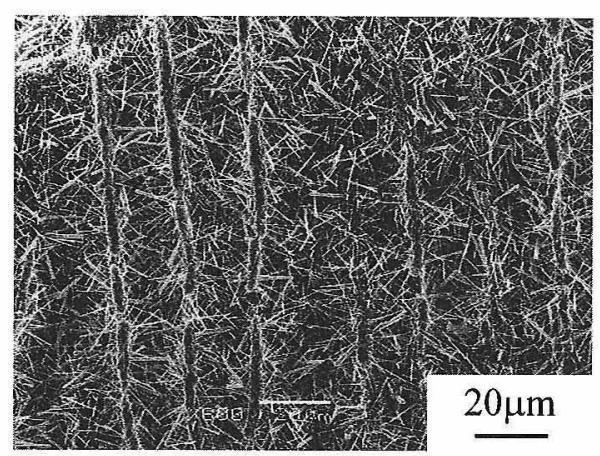

(b)

Fig. 3. Typical microstructure of porous $\mathrm{Si}_{3} \mathrm{~N}_{4}$ ceramic (SN-2) synthesized by freeze-drying process. (a) Top view, (b) internal wall of the macroscopically aligned pore.

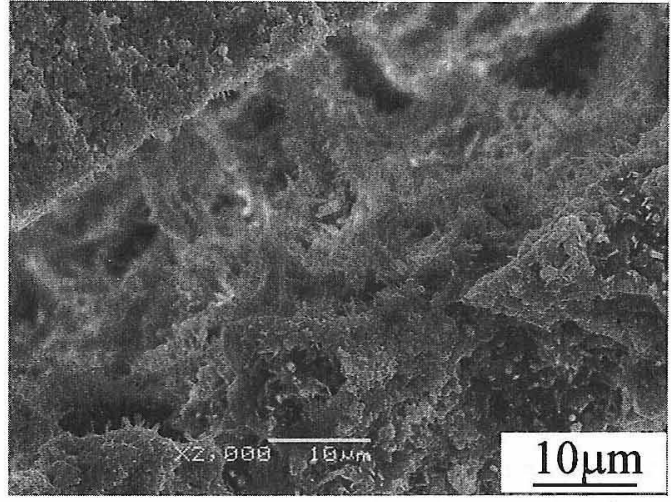

(a)

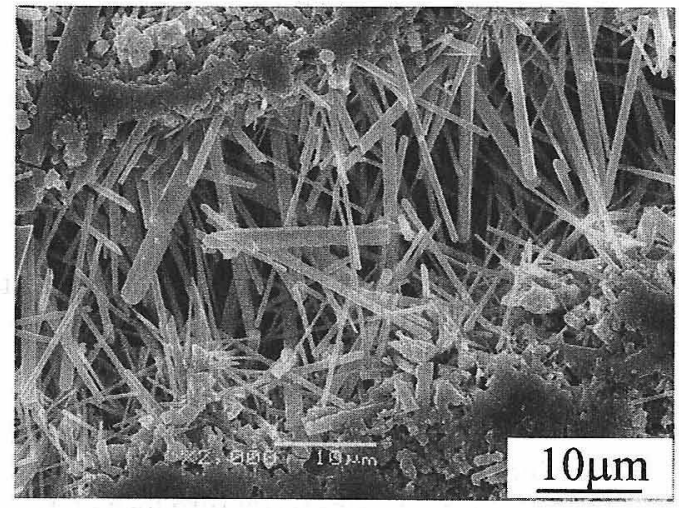

(b)

Fig. 4. Typical microstructure around an aligned open pore of porous $\mathrm{Si}_{3} \mathrm{~N}_{4}$ synthesized by the freeze-drying process. (a) $\mathrm{SN}-1$, (b) $\mathrm{SN}-2$. A great number of fibrous $\mathrm{Si}_{3} \mathrm{~N}_{4}$ grains protruding from the internal wall of the aligned pore were observed for the material sintered at $1850^{\circ} \mathrm{C}$.

velocity. The pressure drop was low enough in comparison with that of the conventional porous ceramics, with the exception of ceramic foams. It is reported that the pressure loss of ceramic foams is smaller by more than one digit than that of the developed materials.9 ${ }^{9)}$ 10) However, ceramic foams are disadvantageous in terms of mechanical reliability. The pressure drop decreased remarkably with increasing pore size. $\mathrm{SN}-1$ and $\mathrm{SN}-4$ showed different pressure loss though they had almost the same pore size. It is because
SN-4 contained a number of pores larger than $20 \mu \mathrm{m}$ and a lot of minute pores in the matrix. The open pores formed in the wall can improve the permeation of the air. Figure 7 shows a change of the pressure drop by repetition of reverse air-cleaning. The air-cleaning was done every $150 \mathrm{~s}$. The increase in the pressure loss as in the case of SN-2 means that ashes inside the pores were not removed sufficiently by aircleaning. On the other hand, in the case of other materials, pressure loss did not increase and maintained a low value. In 


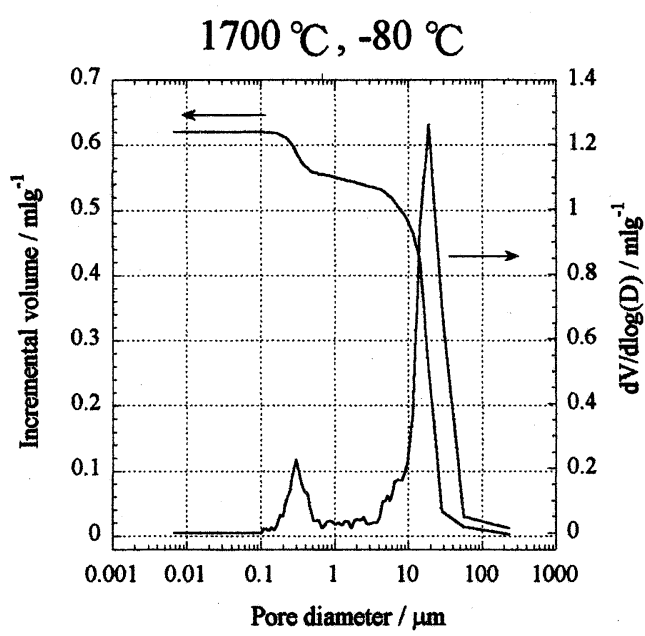

$\mathrm{SN}-1$

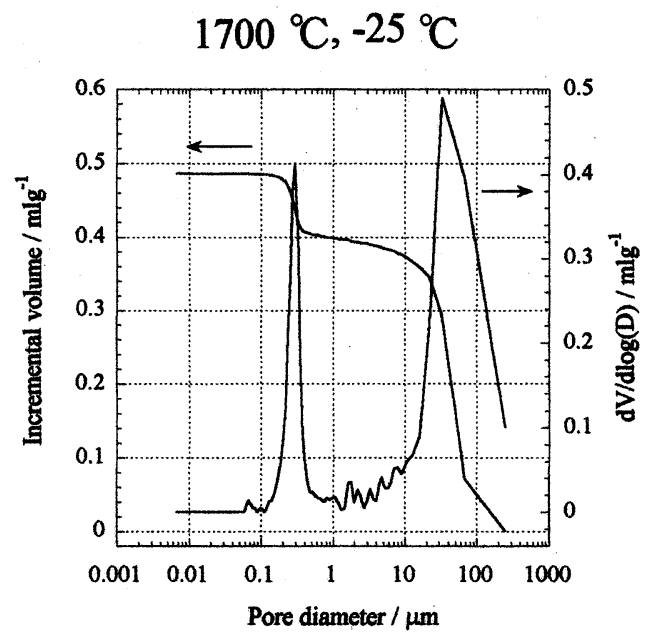

$\mathrm{SN}-3$

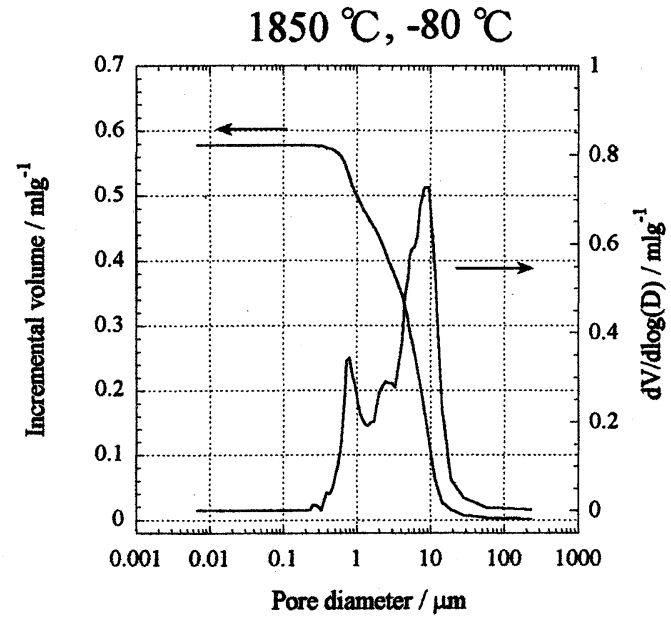

$\mathrm{SN}-2$

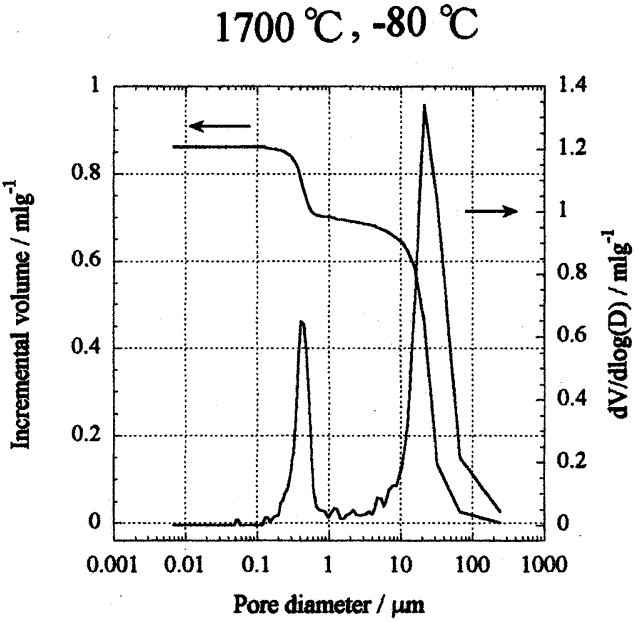

$\mathrm{SN}-4$

Fig. 5. Pore size distribution analyzed by mercury porosimetry. Sintering temperature and freezing temperature are shown in each graph. $\mathrm{SN}-4$ is the material sintered with reduced additives (1Y0.5A).

these cases, air-cleaning worked effectively through the aligned open pores. Therefore, the fibrous texture formed in the aligned pores seemed to have a negative effect on filtering properties. As for this study, it was focused on clarifying the effect of air-cleaning and the mechanical reliability of the material. A change in the pressure loss over time will be evaluated later. Sample appearances before and after the test are shown in Fig. 8. No samples fractured. They had strength sufficient to withstand use. Trapping efficiency of fly ash was almost $100 \%$ for all samples (Table 2). Most ashes were deposited on the porous $\mathrm{Si}_{3} \mathrm{~N}_{4}$ surface. Some ashes seemed to be trapped at the pleat-shaped structure formed on the internal wall of the aligned pores. These ashes could be easily removed by air-cleaning.

This study revealed filtering properties of the porous material with aligned pores. It is possible to reduce pressure loss more by increasing pore size and porosity. Furthermore, the lower the sample thickness, the lower is the pressure loss.

Using the freeze-drying process, porous material with various porosity, pore size and microstructure can be fabricated easily. By controlling these fabrication parameters, porous ceramics with lower pressure loss and higher mechanical reliability can be realized.

This material is expected to be used not only as a filter, but also as a support material for catalysts or absorbents.

\section{Conclusions}

Porous $\mathrm{Si}_{3} \mathrm{~N}_{4}$ with unidirectionally aligned pores was synthesized from a water-based slurry using a freeze-drying process. Porous $\mathrm{Si}_{3} \mathrm{~N}_{4}$ obtained had a characteristic microstructure wherein the macroscopically aligned open pores contained fibrous grains protruding from their internal walls.

Filtering properties of materials were evaluated using a filter tester, and effects of pore size and microstructure on them were investigated. Pressure loss of the materials was smaller than that of conventional porous ceramics, especially when pore size was large. In addition, developed materials were strong enough to stand up to use. The filtering test 


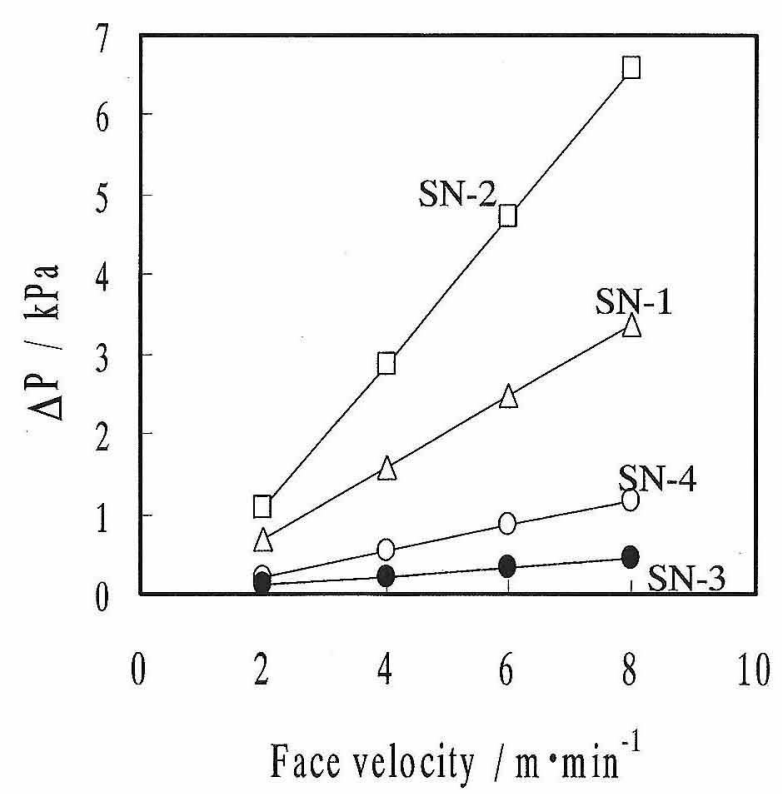

Fig. 6. Pressure drop $(\Delta P)$ of the sample with a face velocity. The pressure drop was much lower than that of conventional porous ceramics with open pores of several micrometers. The pressure drop remarkably decreased with increasing the aligned pore size.

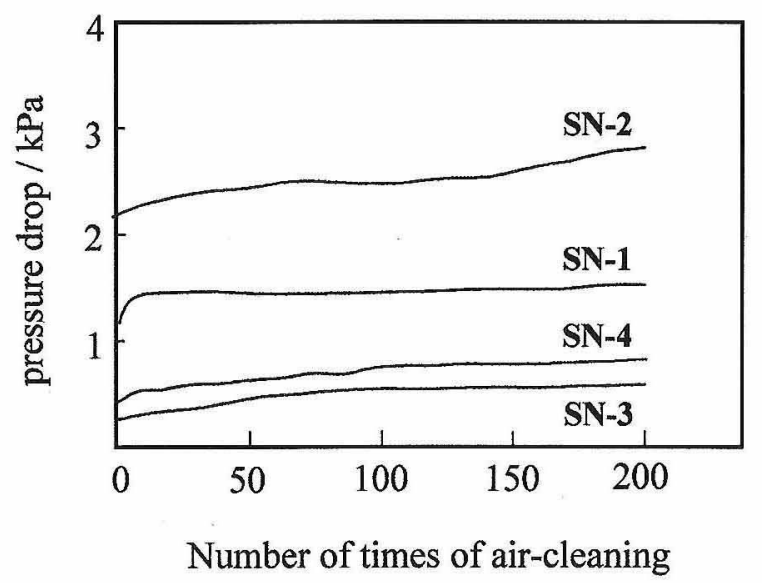

Fig. 7. Change of the pressure drop by repetition of reverse aircleaning. Air-cleaning was done every $150 \mathrm{~s}$.

using fly ash confirmed that the material restrained grain growth of the fibrous texture and could be used repeatedly with periodic reverse air-cleaning. By controlling sample pore size, porosity and thickness, even greater reduction of pressure loss can be expected.

Acknowledgments This work has been supported by the Agency of Industrial Science and Technology (AIST), Ministry of

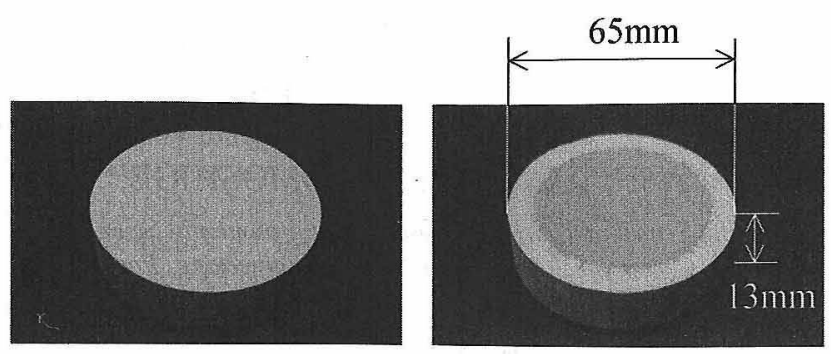

Before

After

Fig. 8. Sample appearance before and after the filtering test.

Table 2. Dust Trapping Efficiency for Filtering Test

\begin{tabular}{cccc}
\hline Sample & $\begin{array}{c}\text { Dust concentration } \\
\text { in vertical flow } \\
/ \mathrm{g} \cdot \mathrm{cm}^{-3}\end{array}$ & $\begin{array}{c}\text { Dust concentration } \\
\text { in horizontal flow } \\
/ \mathrm{g} \cdot \mathrm{cm}^{-3}\end{array}$ & $\begin{array}{c}\text { Trapping efficiency } \\
/ \%\end{array}$ \\
\hline $\mathrm{SN}-1$ & 5.5 & $0.51 \times 10^{-3}$ & 99.99 \\
$\mathrm{SN}-2$ & 5.5 & $1.02 \times 10^{-3}$ & 99.98 \\
$\mathrm{SN}-3$ & 5.5 & $2.05 \times 10^{-3}$ & 99.96 \\
$\mathrm{SN}-4$ & 5.3 & $2.05 \times 10^{-3}$ & 99.96 \\
\hline
\end{tabular}

Economy, Trade and Industry (METI) Japan, as part of the Synergy Ceramics Project. Part of the work has been supported by the New Energy and Industrial Technology Development Organization (NEDO). The authors are members of the Joint Research Consortium of Synergy Ceramics.

\section{References}

1) Fukasawa, T., Ando, M., Ohji, T. and Kanzaki, S., J. Am. Ceram. Soc., 84, 230-32 (2001).

2) Fukasawa, T., Ando, M. and Ohji, T., Ceramic Transactions, $115,217-26(2000)$.

3) Fukasawa, T., Deng, Z.-Y., Ando, M., Ohji, T. and Kanzaki, S., submitted to J. Am. Ceram. Soc.

4) Fukasawa, T., Deng, Z.-Y., Ando, M. and Ohji, T., J. Ceram. Soc. Japan., 109, 1035-38 (2001).

5) Nikaido, M., Kumazawa, K., Saura, E., Kobayashi, K. and Sugino, M., Kokai-Tokkyo-Koho, Japanese Patent (KokaiTokkyo-Koho, Showa) 57-22157 [in Japanese].

6) Zhang, G.-J., Yang, J.-F. and Ohji, T., J. Am. Ceram. Soc., 84, 1395-97 (2001).

7) Weber, K. and Tomand1, G., Ceram. Forum Int., 75, 22-24 (1998).

8) Yokota, T., Chemical Engineering ( Jpn) , 42, 845-51 (1997) [in Japanese].

9) Ambrogio, M., Saracco, G. and Specchia, V., Chem. Eng. Sci., 56, 1613-21 (2001).

10) Richardson, J. T., Peng, Y. and Remue, D., Applied Catalysis A: General, 204, 19-23 (2000). 